\title{
Comportamento ingestivo de vacas em lactação e de ovinos alimentados com dietas contendo palma forrageira
}

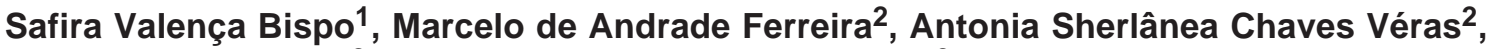 \\ Elisa Cristina Modesto ${ }^{2}$, Amanda Vasconcelos Guimarães ${ }^{3}$, Ricardo Alexandre Silva Pessoa ${ }^{4}$ \\ 1 Programa de Pós-Graduação em Zootenia - UFRPE. \\ 2 Departamento de Zootecnia - UFRPE - Recife - PE. \\ ${ }^{3}$ Graduanda em Zootecnia. \\ ${ }^{4}$ Pesquisador DCR-CNPq.
}

RESUMO - Foram realizados dois experimentos, o primeiro com o objetivo de avaliar o efeito da substituição do feno de capim-elefante por palma forrageira e o segundo para avaliar o efeito da substituição total do milho, e parcial da soja, por palma e ureia sobre o comportamento ingestivo de ovinos e de vacas em lactação, respectivamente. No experimento 1 , foram utilizados cinco ovinos machos, não-castrados, sem raça definida, com peso médio de 25,8 kg, distribuídos em quadrado latino $5 \times 5$. No experimento 2 , foram utilizadas 8 vacas em lactação, com produção média inicial de $14 \mathrm{~kg}$ leite/dia, distribuídas em dois quadrados latino $4 \times 4$. A observação dos dados comportamentais foi realizada visualmente, durante 24 horas, em ambos os experimentos. No experimento 1, com a inclusão da palma forrageira, os consumos de matéria seca, o tempo de alimentação e as eficiências de ruminação aumentaram linearmente, ao passo que o tempo de ruminação reduziu, linearmente também; o consumo de fibra em detergente neutro $(\mathrm{FDN})$ e as eficiências de alimentação apresentaram comportamento quadrático. No experimento 2, a inclusão de palma e ureia não influenciou os consumos de matéria seca e FDN nem os tempos de alimentação e ruminação e as eficiências de alimentação e de ruminação (kgMS/hora), no entanto, a eficiência de ruminação (kg FDN/hora) apresentou comportamento quadrático. O tempo de mastigação total e o tempo de ócio não foram influenciados pela inclusão de palma na dieta nos dois experimentos. Recomenda-se para ração de ruminantes com alta proporção de palma forrageira a inclusão de uma fonte de fibra fisicamente efetiva.

Palavras-chave: alimentação, fibra, ruminação, ócio

\section{Ingestive behavior of lactating cows and sheep fed diets with spineless cactus}

ABSTRACT - It was carried out two experiments, the first aiming to assess the effect of substituting elephant grass hay by spineless cactus and the second to evaluate the total replacement of corn and partial replacement of soybean by cactus and urea regarding to the ingestion behavior of sheep and lactating cows, respectively. In experiment 1 , five mixedbreed non castrated male sheep with $25.8 \mathrm{~kg}$ average weight were distributed in a $5 \times 5$ latin square. In experiment 2, it was used eight lactating cows $14 \mathrm{~kg}$ milk/day average initial production distributed in two $4 \times 4$ latin squares. The observation of the behavioral data was visually performed for a period of 24 hours in both experiments. In experiment 1 , the intake of dry matter, feeding time and rumination efficiency increased linearly with the inclusion of the spineless cactus, whereas rumination time decreased linearly; the consumption of neutral detergent fiber (NDF) and feeding efficiency exhibited quadratic behavior. In experiment 2, the inclusion of cactus and urea had no influence on dry matter and NDF intake, neither on time $(\mathrm{kgDM} / \mathrm{h})$ and efficiency of feeding and rumination; however, rumination efficiency (kgNDF/h) exhibited quadratic behavior. Total mastication time and idle time were not influenced by the inclusion of cactus in the diet in both experiments The inclusion of a source of physically effective fiber is recommended for ruminant rations with a high proportion of spineless cactus.

Key Words: feeding, fiber, resting, rumination

\section{Introdução}

Os objetivos de se estudar o comportamento ingestivo do animal são avaliar os efeitos do arraçoamento ou a quantidade e a qualidade nutritiva de alimentos; estabelecer a relação entre comportamento ingestivo e consumo voluntário, e averiguar o uso potencial do conhecimento sobre o comportamento ingestivo para melhoria do desempenho animal (Albright, 1993). Neste sentido, os estudos referentes ao comportamento são importantes para 
melhoria do manejo, nutrição e melhoramento animal (Muller et al., 1994). No entanto, o estudo do comportamento ingestivo dos ruminantes ainda é novo no Nordeste brasileiro e merece atenção por fornecer subsídios sobre as interações entre as práticas de arraçoamento, manejo e as condições edafoclimáticas (Pires, 2003).

O semiárido nordestino é caracterizado pela escassez, irregularidade e má distribuição de chuvas, as quais são favorecidas por altas temperaturas e elevados índices de evaporação (Amorim et al., 2008). Segundo Lira (1981, essa região apresenta precipitação média anual variando de 500 a 1000 mm, situação que prejudica a produção de forragens. Além disso, a maioria do Estado de Pernambuco, apresenta ITU acima de 75 durante os meses mais quentes do ano (Silva, 2009), que, segundo Rosenberg et al. (1983), é um valor no qual os produtores necessitam tomar providências para evitar perdas (sombreamento, arrefecimento etc).

Portanto, a procura por forrageiras adaptadas a essas condições climáticas é essencial para melhoria da produtividade da pecuária desta região. Assim, as Opuntias são forrageiras de elevada importância para cobertura do solo das zonas áridas e semi-áridas, por sobreviverem e se propagarem em condições de pouca chuva e altas temperaturas (Reynolds \& Arias, 2001; Nobel, 2001).

Objetivou-se avaliar o efeito da substituição do feno de capim-elefante por palma forrageira sobre o comportamento ingestivo e o consumo de nutrientes em ovinos e estudar o efeito da substituição total do milho e parcial da soja por palma forrageira e ureia sobre o comportamento ingestivo, o consumo de nutrientes e a produção de leite de vacas em lactação.

\section{Material e Métodos}

Foram realizados dois experimentos, o primeiro no Departamento de Zootecnia da Universidade Federal Rural de Pernanbuco, durante o período de outubro de 2005 a janeiro de 2006, em Recife, Pernambuco. Foram utilizados cinco ovinos com aptidão para carne, sem padrão racial definido, não-castrados e em crescimento, com peso vivo médio de 25,8 kg, mantidos em gaiolas individuais para ensaios metabólicos, com comedouro, bebedouro e cocho para fornecimento de mistura mineral.

Os animais foram distribuídos em quadrado latino $5 \times 5$ (5 períodos, 5 níveis de palma e 5 animais). Cada período teve duração de 13 dias, sendo sete para adaptação e seis para coleta dos dados e amostras. As dietas experimentais foram balanceadas com base nos resultados das análises químico-bromatológica dos ingredientes (Tabela 1), para atender às exigências nutricionais de pequenos ruminantes recomendadas pelo NRC (2007). O feno foi originado de um capim-elefante senescente e composto da planta inteira, sendo confeccionado no Instituto Agronômico de Pernambuco (IPA), na Estação Experimental de Arcoverde. As dietas experimentais consistiram de rações completas de volumoso e concentrado com cinco níveis de inclusão palma (Opuntia fícus indica, Mill) em substituição ao feno de capim-elefante (Tabela 2).

O segundo experimento foi realizado no Instituto de Pesquisa Agropecuária (IPA), localizado em Arcoverde, Pernambuco, no período de julho a outubro de 2007. Foram utilizadas oito vacas mestiças (3/8 HZ) na terceira lactação, com peso médio de $540 \mathrm{~kg}$, período de lactação em torno de 100 dias e produção média inicial de 14 kg leite/dia, distribuídas em dois quadrados latino $4 \times 4$. Cada período experimental teve duração de 15 dias, sendo 10 para adaptação dos animais e 5 para coleta dos dados e amostras. Os animais foram mantidos em baias individuais com piso de alvenaria, dotados de cochos e bebedouros para o controle do consumo de alimentos e água.

Os animais foram mantidos em baias individuais com piso de alvenaria, com cochos e bebedouros para controle do consumo de alimentos e água. As dietas experimentais foram balanceadas com base nos resultados das análises químico-bromatológica dos ingredientes, para atender às exigências nutricionais recomendadas pelo NRC (2001) para vacas em lactação.

O arraçoamento dos animais, nos dois experimentos, foi feito duas vezes ao dia na forma de ração completa. A quantidade de ração fornecida diariamente foi ajustada de acordo com o consumo do dia anterior, de modo que houvesse sobras em torno de $10 \%$ do total fornecido, a fim de proporcionar ingestão voluntária e não alterar a proporção dos ingredientes.

Durante o período de coleta, amostras dos alimentos fornecidos, bem como das sobras, foram recolhidas diariamente pela manhã, armazenadas e congeladas para posterior processamento. Ao final do experimento, foi feita amostra composta por animal e por período. Posteriormente, todas as amostras foram pré-secas em estufa de ventilação forçada, moídas passando por peneira de malha de $2 \mathrm{~mm}$ de diâmetro, e submetidas à análises bromatológicas no Laboratório de Nutrição Animal do Departamento de Zootecnia da Universidade Federal Rural de Pernambuco.

As observações referentes ao comportamento animal foram realizadas de forma visual, durante um período de 24 horas, pelo método de varredura instantânea, proposto por Martin \& Bateson (1986), a intervalos de 5 minutos e 10 minutos para ovinos e vacas, respectivamente. As variáveis 
Tabela 1 - Composição nutricional dos ingredientes usados nas dietas experimentais

\begin{tabular}{|c|c|c|c|c|c|c|c|}
\hline \multirow[t]{2}{*}{ Ingrediente } & \multicolumn{6}{|c|}{ Parâmetro nutricional } & \multirow[b]{2}{*}{$\begin{array}{c}\text { Carboidratos } \\
\text { não-fibosos } \\
\text { (\% da MS) }\end{array}$} \\
\hline & $\begin{array}{l}\text { Matéria } \\
\text { seca (\%) }\end{array}$ & $\begin{array}{l}\text { Matéria } \\
\text { orgânica } \\
\text { (\% da MS) }\end{array}$ & $\begin{array}{l}\text { Proteína } \\
\text { bruta } \\
\text { (\% da MS) }\end{array}$ & $\begin{array}{c}\text { Extrato } \\
\text { etéreo } \\
\text { (\% da MS) }\end{array}$ & $\begin{array}{l}\text { Fibra em } \\
\text { detergente neutro } \\
(\% \text { da MS) }\end{array}$ & $\begin{array}{c}\text { Carboidratos } \\
\text { totais } \\
\text { (\% da MS) }\end{array}$ & \\
\hline \multicolumn{8}{|c|}{ Experimento 1} \\
\hline Palma forrageira & 9,39 & 88,25 & 4,90 & 2,48 & 32,80 & 80,87 & 48,07 \\
\hline Feno de capim-elefante & 87,75 & 92,97 & 5,85 & 2,14 & 80,67 & 84,98 & 4,31 \\
\hline Farelo de soja & 89,00 & 93,14 & 49,59 & 1,74 & 16,60 & 41,81 & 25,21 \\
\hline \multicolumn{8}{|c|}{ Experimento 2} \\
\hline Palma forrageira & 8,28 & 85,62 & 3,04 & 2,00 & 28,13 & 80,57 & 52,44 \\
\hline Feno de capim-elefante & 90,39 & 88,86 & 4,70 & 1,22 & 77,75 & 82,93 & 5,19 \\
\hline Farelo de soja & 87,94 & 93,43 & 51,55 & 2,34 & 19,15 & 39,54 & 20,37 \\
\hline Fubá de milho & 87,24 & 97,95 & 8,46 & 3,99 & 13,90 & 85,50 & 71,61 \\
\hline
\end{tabular}

comportamentais observadas e registradas foram: ócio, ruminação e tempo gasto com alimentação. Foram calculadas as seguintes relações: EAL = consumo de MS, em kg/tempo de alimentação, em horas; EAL = consumo de FDN em kg/tempo de alimentação, em horas; ERU = consumo de MS em kg/tempo de ruminação, em horas; ERU = consumo de FDN em kg/tempo de ruminação, em horas; TMT = tempo de alimentação + tempo de ruminação, em horas; em que EAL = eficiência de alimentação; ERU = eficiência de ruminação e TMT = tempo de mastigação total.

As indicações para as determinações de matéria seca (MS), matéria mineral (MM), proteína bruta (PB) e extrato etéreo (EE) foram feitas com base em Silva e Queiroz (2002). Para determinação das fibras em detergente neutro (FDN) e em detergente ácido (FDA) foi adotada a metodologia descrita e recomendada pelo fabricante do aparelho ANKON, utilizando sacos de tecido-não-tecido (TNT $100 \mathrm{~g} / \mathrm{m}^{2}$ ) com dimensões de $4 \times 5 \mathrm{~cm}$, confeccionados no
Laboratório de Nutrição Animal. A substituição do tecido F57 (Ankom ${ }^{\circledR}$ ) por TNT (tecido não tecido) é uma alternativa de menor custo para quantificação de compostos fibrosos indigestíveis em alimentos, uma vez que apresenta, em geral, estimativas com níveis similares de exatidão e precisão (Casali et al., 2009).

Para estimativa dos carboidratos totais (CHT) foi utilizada a equação proposta por Sniffen et al. (1992), como $\mathrm{CHT}=100-(\mathrm{PB}+\mathrm{EE}+\mathrm{MM})$, e para estimativa dos carboidratos não-fibrosos (CNF) foi usada equação proposta por Mertens (1997), como CNF = CHT - FDN. Os resultados obtidos foram analisados estatisticamente por meio de análises de variância e de regressão em função dos níveis de palma forrageira, utilizando-se o sistema de Análise Estatística e Genética SAEG (UFV, 1998). Os critérios utilizados para escolha do modelo foram o nível de significância (5\%), o coeficiente de determinação ( $\mathrm{r}^{2}$ ) e o fenômeno biológico.

Tabela 2 - Composição das dietas do experimento 1

\begin{tabular}{|c|c|c|c|c|c|}
\hline & \multicolumn{5}{|c|}{ Nível de palma forrageira (\%) } \\
\hline & 0 & 14 & 28 & 42 & 56 \\
\hline \multicolumn{6}{|l|}{ Ingrediente } \\
\hline Palma forrageira & 0 & 14 & 28 & 42 & 56 \\
\hline Fubá de milho & 20 & 19,32 & 18,64 & 17,96 & 17,28 \\
\hline Farelo de soja & 15 & 15,68 & 16,36 & 17,04 & 17,72 \\
\hline Matéria orgânica (\% da MS) & 94,17 & 93,44 & 92,77 & 92,07 & 91,37 \\
\hline Proteína bruta (\% da MS) & 13,40 & 13,54 & 13,68 & 13,78 & 13,92 \\
\hline Extrato etéreo (\% da MS) & 2,64 & 2,66 & 2,69 & 2,72 & 2,74 \\
\hline Fibra em detergente neutro (\% da MS) & 58,14 & 51,34 & 44,54 & 37,74 & 30,94 \\
\hline Fibra em detergente ácido (\% da MS) & 38,69 & 34,44 & 30,20 & 25,95 & 21,70 \\
\hline Carboidratos totais (\% da MS) & 78,12 & 77,26 & 76,39 & 75,57 & 74,70 \\
\hline
\end{tabular}


Tabela 3 - Composição das dietas do experimento 2

\begin{tabular}{|c|c|c|c|c|}
\hline & \multicolumn{4}{|c|}{ Nível de palma forrageira (\%MS) } \\
\hline & 45 & 50 & 55 & 60 \\
\hline \multicolumn{5}{|l|}{ Composição em ingredientes } \\
\hline Feno de capim elefante & 30 & 30 & 30 & 30 \\
\hline Palma forrageira & 45 & 50 & 55 & 60 \\
\hline Fubá de milho & 9,3 & 6,2 & 3,1 & 0 \\
\hline Farelo de soja & 14 & 11,63 & 9,25 & 6,88 \\
\hline Ureia & 0,2 & 0,68 & 1,15 & 1,63 \\
\hline Mistura mineral & 1,5 & 1,5 & 1,5 & 1,5 \\
\hline \multicolumn{5}{|l|}{ Composição nutricional (calculada) } \\
\hline Matéria seca (\%) & 16,53 & 15,16 & 14,00 & 13,01 \\
\hline Matéria orgânica (\% da MS) & 48,53 & 52,43 & 56,34 & 60,23 \\
\hline Proteína bruta (\% da MS) & 11,34 & 11,35 & 11,33 & 11,35 \\
\hline Extrato etéreo (\% da MS) & 1,96 & 1,88 & 1,81 & 1,73 \\
\hline Fibra em detergente neutro (\% da MS) & 39,96 & 40,48 & 41 & 41,52 \\
\hline Carboidratos totais (\% da MS) & 74,62 & 75,06 & 75,5 & 75,94 \\
\hline Carboidratos não-fibrosos (\% da MS) & 34,67 & 34,58 & 34,5 & 34,42 \\
\hline
\end{tabular}

\section{Resultados e Discussão}

O consumo de MS pelos ovinos aumentou linearmente à medida que a palma era incluída na dieta, comportamento provavelmente relacionado à maior digestibilidade, decorrente do aumento dos carboidratos não-fibrosos (Tabela 2), proporcionando maior consumo, à medida que a palma era incluída na dieta. Segundo Felker (1995), a digestibilidade aparente da MS da palma forrageira é em torno de 75\%.

Nesse mesmo raciocínio, Mertens (1987) afirmou que, em dietas com níveis mais elevados de fibra, o principal fator que controla o consumo é a capacidade física da ingestão, ou seja, o enchimento ruminal. Logo, poderia ter ocorrido limitação na ingestão nos primeiros tratamentos, devido aos teores de fibras em detergente neutro das dietas serem mais altos (Tabela 2). Outro fator que pode ter influenciando é a palatabilidade da palma forrageira que, segundo Gebremariam et al. (2006), é alta, proporcionando assim maiores consumos com a inclusão desta forrageira. Apesar da alta inclusão de palma forrageira na dieta (56\%) não foi observado meteorismo nos animais.

Para o consumo de fibra em detergente neutro (FDN), em kg/dia (Tabela 4), não foi observado efeito da substituição do feno por palma forrageira $(\mathrm{P}>0,05)$. E provavelmente esse comportamento se justifique pelo aumento no consumo de matéria seca, compensando a diminuição nos teores de fibra em detergente neutro à medida que se incluía palma forrageira.

Tabela 4 - Efeito da inclusão de palma forrageira sobre o comportamento ingestivo de ovinos

\begin{tabular}{|c|c|c|c|c|c|c|c|c|}
\hline & \multicolumn{5}{|c|}{ Nível de palma (\%) } & \multirow[t]{2}{*}{$\mathrm{CV}(\%)$} & \multicolumn{2}{|c|}{ Efeito } \\
\hline & 0 & 14 & 28 & 42 & 56 & & Linear & Quadrático \\
\hline Consumo de matéria seca (kg/dia) & 0,64 & 0,81 & 1,09 & 1,14 & 1,15 & 24,39 & 0,00 & NS \\
\hline Consumo de FDN (kg/dia) & 0,35 & 0,39 & 0,47 & 0,43 & 0,36 & 28,97 & NS & NS \\
\hline Tempo de ruminação (horas/dia) & 6,82 & 6,67 & 6,98 & 6,00 & 4,53 & 23,05 & 0,02 & NS \\
\hline Tempo de alimentação (horas/dia) & 3,25 & 2,50 & 3,35 & 3,90 & 4,38 & 31,77 & 0,04 & NS \\
\hline Tempo de ócio (horas/dia) & 13,80 & 15,83 & 13,43 & 13,85 & 14,88 & 16,19 & NS & NS \\
\hline Eficiência de alimentação (kg MS/hora) & 0,21 & 0,34 & 0,34 & 0,35 & 0,28 & 33,78 & NS & 0,04 \\
\hline Eficiência de alimentação (kg FDN/hora) & 0,11 & 0,16 & 0,15 & 0,14 & 0,082 & 36,00 & NS & 0,03 \\
\hline Eficiência de ruminação (kg MS/hora) & 0,10 & 0,13 & 0,16 & 0,20 & 0,27 & 27,68 & 0,00 & NS \\
\hline Eficiência de ruminação (kg FDN/hora) & 0,55 & 0,60 & 0,68 & 0,76 & 0,86 & 24,33 & 0,00 & NS \\
\hline \multirow[t]{2}{*}{ Tempo de mastigação total (hora/dia) } & 10,07 & 9,17 & 10,33 & 9,90 & 8,92 & 19,19 & NS & NS \\
\hline & \multicolumn{6}{|c|}{ Equação de regressão } & & $\mathrm{r}^{2}$ \\
\hline Consumo de MS (kg/dia) & \multicolumn{7}{|c|}{$\mathrm{y}=0,6991+0,0096 \mathrm{PF}$} & 0,85 \\
\hline Tempo de alimentação (horas/dia) & \multicolumn{7}{|c|}{$\mathrm{Y}=7,2464-0,0374 \mathrm{PF}$} & 0,68 \\
\hline Tempo de ócio (horas/dia) & \multicolumn{7}{|c|}{$y=2,7433+0,0262 P F$} & 0,66 \\
\hline Eficiência de alimentação (kg MS/hora) & \multicolumn{7}{|c|}{$\mathrm{y}=0,219+0,0091 \mathrm{PF}-0,00014 \mathrm{PF}^{2}$} & 0,93 \\
\hline Eficiência de alimentação (kg FDN/hora) & \multicolumn{7}{|c|}{$\mathrm{y}=0,12+00035 \mathrm{PF}-0,000074 \mathrm{PF}^{2}$} & 0,95 \\
\hline Eficiência de ruminação (kg MS/hora) & \multicolumn{7}{|c|}{$\mathrm{y}=0,090476+0,0028996 \mathrm{PF}$} & 0,95 \\
\hline Eficiência de ruminação (kg FDN/hora) & \multicolumn{7}{|c|}{$\mathrm{y}=0,056026+0,0003687 \mathrm{PF}$} & 0,99 \\
\hline
\end{tabular}


O tempo de ruminação diminuiu linearmente, possivelmente devido à diminuição da fibra em detergente neutro na dieta total e consequente aumento dos carboidratos -não-fibrosos provenientes da palma (Tabela 2). Segundo Van Soest (1991), a atividade de ruminação em animais adultos ocupa cerca de oito horas por dia com variações entre 4 e 9 horas. Esse comportamento é principalmente influenciado pela natureza da dieta e parece ser proporcional ao teor de parede celular dos alimentos volumosos, sendo a efetividade da fibra, fator primordial para estímulo da mastigação (Grant, 1995). Além disso, como discutido anteriormente, devido ao aumento linear no consumo de matéria seca pode-se inferir que a digestibilidade foi aumentada, já que o feno de capim-elefante foi substituído pela palma forrageira, alimento de maior digestibilidade (Bispo et al., 2007), proporcionando, desta forma, menor tempo de permanência do alimento no rúmen.

No entanto, apesar da diminuição no tempo de ruminação, Bispo et al. (2007), trabalhando com os mesmos animais, observaram aumento linear nos coeficientes de digestibilidade da matéria seca e da matéria orgânica, e diminuição proporcional nas concentrações de $\mathrm{NH}_{3}$ ruminal, permitindo inferir que, com a substituição de feno de capimelefante por palma forrageira, houve melhor equilíbrio entre energia e proteína no ambiente ruminal. Além disso, com $56 \%$ de inclusão de palma na dieta, o pH foi de 6,24, próximo à faixa de $\mathrm{pH}$ ideal de 6,2 a 7,0 preconizada por Hoover (1986) para que não ocorra prejuízos na digestão.

O tempo de alimentação com a inclusão de palma apresentou comportamento crescente; fator que pode ser explicado pelo aumento no consumo de matéria seca com a inclusão de palma na dieta, assim, maiores quantidade de matéria natural foram ofertadas. Vale salientar que, com 56\% de inclusão de palma, os animais chegaram a consumir 714 g de matéria seca de palma forrageira por dia.
Não houve influência da inclusão de palma sobre os tempos de ócio e de mastigação total $(\mathrm{P}>0,05)$. Certamente, isso foi observado porque os tempos de alimentação e ruminação apresentaram respostas inversas de aumento e de diminuição, respectivamente.

As eficiências de alimentação (kg MS/hora e kg FDN/hora) foram influenciadas de forma quadrática pelo aumento de palma na dieta. Sendo a eficiência máxima estimada em $0,364 \mathrm{~kg} /$ hora com 32,5\% de palma forrageira na dieta e $0,160 \mathrm{~kg} /$ hora com 23,6\% de palma forrageira na dieta em função do nível de matéria seca e matéria orgânica, respectivamente.

As eficiências de ruminação em kg MS/h e kg FDN/hora aumentaram linearmente. Segundo Dulphy et al. (1980), elevando-se o nível de inclusão de carboidratos não fibrosos na dieta aumenta-se a eficiência de ruminação. Tal fato foi verificado no trabalho de Bürger et al. (2000), em que a eficiência de ruminação aumentou linearmente com a inclusão de concentrado nas dietas. Logo, com a inclusão de palma forrageira há diminuição na fibra em detergente neutro da dieta, levando o animal a ser mais eficiente no uso da fibra por unidade de tempo.

O consumo de matéria seca (CMS) não foi influenciado pela inclusão de palma e ureia na dieta $(\mathrm{P}>0,05)$. A regulação do consumo é complexa e inclui limitações físicas, controle fisiológico e fatores psicogênicos. Fatores físicos incluem a distenção, causando sensação de enchimento, concentração da fibra em detergente neutro e composição da dieta que afetam as taxas de digestão, tempo na redução do tamanho da partícula e passagem da digesta. Fatores fisiológicos incluem controle da fome e saciedade pela região hipotalâmica do cérebro, além de fatores psicogênicos, os quais englobam o comportamento do rebanho, a palatabilidade do alimento, os fatores ambientais e o stress (Doughterty \& Collins, 2003).

Tabela 5 - Desempenho e comportamento ingestivo de vacas em lactação alimentadas com dietas contendo palma forrageira

\begin{tabular}{|c|c|c|c|c|c|c|c|}
\hline & \multicolumn{4}{|c|}{ Nível de palma forrageira (\%) } & \multirow[t]{2}{*}{$\mathrm{CV}$} & \multicolumn{2}{|c|}{ Efeito } \\
\hline & 45 & 50 & 55 & 60 & & Linear & Quadrático \\
\hline Consumo de MS (kg/dia) & 16,92 & 16,58 & 16,87 & 16,40 & 6,70 & NS & NS \\
\hline Consumo de FDN (kg/dia) & 6,70 & 6,70 & 7,00 & 6,88 & 7,51 & NS & NS \\
\hline Produção de leite (kg/dia) & 13,51 & 13,04 & 12,25 & 11,54 & 5,29 & 0,001 & NS \\
\hline Tempo de ruminação (horas/dia) & 7,98 & 7,17 & 7,28 & 7,00 & 15,80 & NS & NS \\
\hline Tempo de alimentação (horas/dia) & 5,08 & 4,63 & 4,88 & 5,35 & 13,90 & NS & NS \\
\hline Tempo de ócio (horas/dia) & 10,94 & 12,21 & 11,91 & 11,65 & 9,30 & NS & NS \\
\hline Eficiência de alimentação (kg MS/hora) & 3,51 & 3,61 & 3,79 & 3,16 & 16,54 & NS & NS \\
\hline Eficiência de alimentação (kg FDN/hora) & 1,39 & 1,46 & 1,56 & 1,33 & 16,42 & NS & NS \\
\hline Eficiência de ruminação (kg MS/hora) & 2,16 & 2,37 & 2,39 & 2,42 & 13,47 & NS & NS \\
\hline Eficiência de ruminação (kg FDN/hora) & 0,85 & 0,95 & 0,98 & 1,00 & 13,75 & 0,03 & NS \\
\hline \multirow[t]{2}{*}{ Tempo de mastigação total (horas/dia) } & 13,06 & 11,80 & 12,08 & 12,35 & 8,85 & NS & NS \\
\hline & \multicolumn{4}{|c|}{ Equação } & & & $r^{2}$ \\
\hline Produção de leite (kg/dia) & \multicolumn{4}{|c|}{$Y=14,264-0,6709 P F$} & & & 0,99 \\
\hline Eficiência de ruminação (kg FDN/hora) & \multicolumn{4}{|c|}{$\mathrm{Y}=0,8262+0,0492 \mathrm{PF}$} & & & 0,88 \\
\hline
\end{tabular}


Melo et al. (2002) sugeriram que a ureia pode provocar diminuição no consumo de matéria seca, devido aos efeitos metabólicos e/ou a palatabilidade (sabor amargo). Ainda, de acordo com Pereira et al. (2003), o tamanho e a condição corporal, bem como a raça, o estado fisiológico e as características da dieta são fatores que influenciam no consumo de matéria seca. Além disso, o NRC (2001) indica uma suposta relação negativa entre umidade e consumo de matéria seca.

Neste sentido, Gebremariam et al. (2006), trabalhando com ovinos, ofereceram quatro níveis de palma em substituição ao feno $(0 ; 22,84 ; 45,69$ e 68,53\%) e observaram aumento no consumo de matéria seca até $23,83 \%$ de inclusão de palma. Sendo a queda observada no consumo de matéria seca a partir deste ponto, atribuída à distenção física do rumem provocada pelo grande volume de água consumido via palma, o qual mais que duplica entre o tratamento com $22,84 \%$ e $45,69 \%$ de inclusão de palma.

No entanto, o NRC (2001) sugere mínimo de 25\% de fibra em detergente neutro na dieta para vacas de leite, e devido ao fato de ainda não existir uma recomendação pra ovinos, esse parâmetro é utilizado para o balanceamento de dietas para estes últimos também. Assim, no trabalho acima citado, com $68,53 \%$ de palma, a quantidade de fibra em detergente neutro é aproximadamente $23,5 \%$, sugerindo um possível desbalanceamento entre fibra em detergente neutro e carboidratos-não-fibrosos, podendo isso ter causado alterações no padrão de fermentação ruminal, com diminuição no consumo de matéria seca.

Bispo et al. (2007), quando substituíram a palma forrageira por feno de capim-elefante (0, 14, 28, 42 e 56\%) em dietas de ovinos, justificaram o comportamento crescente de matéria seca pelo aumento da digestibilidade e da palatabilidade da dieta com a inclusão da palma. Mas é possível observar que, com 56\% de palma na dieta, os níveis de fibra em detergente neutro e carboidratos-não-fibrosos se mantiveram dentro do limite preconizado para vacas de leite (NRC, 2001). Do mesmo modo, respeitando os limites propostos pelo NRC (2001), Wanderley et al. (2002), trabalhando com vacas da raça holandesa em lactação, substituíram silagem de sorgo por palma (0; 12; 24 e 36\% MS) e não observaram efeito no consumo de matéria seca e produção de leite.

Destaca-se que a inclusão de palma forrageira e ureia não alterou a palatabilidade da dieta (Ferreira, 2005) e, como os níveis de ureia não foram muito altos, seu efeito pode ter sido atenuado. Além disso, a proporção de feno de capimelefante foi a mesma entre as dietas experimentais (Tabela 3). Outro ponto importante é que a palma apresenta alta fibra fisicamente efetiva e, conforme Oliveira et al. (2001), a fibra fisicamente efetiva está relacionada à saúde do animal, basicamente pela manutenção do $\mathrm{pH}$ ruminal adequado através do aporte de saliva durante a ingestão e ruminação. Desta forma, provavelmente houve estímulo da salivação e consequente manutenção do pH ruminal, possibilitando ambiente ruminal adequado para os microorganismos ruminais em todos os diferentes níveis de palma (Tabela 3).

O consumo de fibra em detergente neutro não foi influenciado pela inclusão de palma e ureia na dieta $(\mathrm{P}>0,05)$, possivelmente devido ao comportamento observado no consumo de matéria seca e concentração de fibra em detergente neutro (Tabela 3) com a inclusão de palma e ureia. Resultado semelhante foi encontrado quando Silva et al. (2005) e Assis et al. (2004) trabalhavam com alimentos de composição próxima à da palma forrageira, quando foi substituída a silagem de sorgo por xiquexique $(0,12,5 ; 25,0 ; 37,5$ e $50 \%)$ e fubá de milho por polpa cítrica (0,33, 67 e 100\%) na dieta de vacas em lactação, respectivamente. Também Melo et al. (2003) e Véras et al. (2005) não encontraram efeito no consumo de fibra em detergente neutro quando substituíram parcialmente o farelo de soja por palma e ureia para vacas em lactação e milho por farelo de palma na dieta de ovinos, respectivamente.

É possível notar que com a substituição total do milho e parcial da soja por palma forrageira e ureia, a produção de leite (PL) diminuiu linearmente. Este resultado decrescente na produção de leite deve-se, provavelmente, ao excesso de proteína degradada no rúmen (PDR), causado pelo aumento de ureia nas dietas. E, segundo Sater \& Roffler (1975), quando a produção de amônia excede a habilidade das bactérias do rumem em convertê-la em proteína microbiana, a amônia derivada do nitrogênio não proteico (NNP) e da degradação da proteína verdadeira não terá qualquer valor no fornecimento de aminoácidos, sendo necessário que parte da proteína da dieta escape da degradação ruminal e passe para o intestino delgado para suprir as necessidades adequadas de aminoácidos, pois as bactérias e os protozoários não produzem proteína suficiente para máxima produção de leite (Chalupa \& Sniffen, 1991).

Desta forma, conforme o NRC (2001), vacas com produção em torno de $14 \mathrm{~kg}$ de leite/dia e $540 \mathrm{~kg}$ de peso vivo apresentam exigência próxima a 44,35\% da PB dietética em proteína não degradada no rúmen (PNDR). No entanto, com a substituição do farelo de soja, que possui em média 49,22\% de PNDR (Hernadéz et al., 2002), pela ureia, que não possui proteína não degradada no rúmen (PNDR), pode ter ocorrido diminuição dos percentuais de proteína não degradada no rúmen das dietas, o que, provavelmente, ocasionou a redução da produção de leite. E, segundo o NRC (2001), limitações de proteína não degradada no rúmen 
são acompanhadas de limitações em aminoácidos essenciais, principalmente metionina e lisina, na proteína metabolizável, o que também poderia ter promovido a diminuição da produção de leite.

A adição de palma e ureia não alterou os tempos de ruminação e alimentação, $(\mathrm{P}>0,05)$ provavelmente devido ao fator de que o consumo de matéria seca e fibra em detergente neutro não foi influenciado com a inclusão de palma, bem como a concentração de fibra em detergente neutro das dietas experimentais (Tabela 3). Resultado semelhante foi encontrado por Lima (2003), quando substituiu o milho por palma na dieta de vacas em lactação e não observou mudanças nos tempos despendidos com ruminação e alimentação.

Os tempos despendidos com ócio e mastigação total não foram influenciados $(\mathrm{P}>0,05)$ pela inclusão de palma e ureia na dieta. O tempo médio despendido com ócio e tempo de mastigação total (TMT) estão de acordo com Albright (1993) e Carvalho et al. (2004), para os quais o tempo médio gasto com ócio e mastigação total gira em torno de 10,50 e 12,60, respectivamente.

Colenbranden et al. (1991) citaram que a atividade de mastigação (TMT) é uma resposta à efetividade da fibra, portanto, é possível constatar que a substituição de grande parte do concentrado por palma forrageira não modifica o tempo de mastigação, mostrando, assim, a falta de efetividade da fibra em detergente neutro da palma.

A eficiência de alimentação (kg MS e FDN/hora) e a eficiência de ruminação ( $\mathrm{kg}$ MS/h) não foram influenciadas pela inclusão de palma e ureia. Os valores médios das eficiências de alimentação foram 3,52 e 1,43 kg/hora, para as frações matéria seca e fibra em detergente neutro, respectivamente e o da eficiência de ruminação 2,33 kg, para a fração matéria seca. Do mesmo modo, Carvalho et al. (2008) avaliaram a inclusão de diferentes níveis (0, 10, 20 e 30\%) de farelo de cacau, alimento rico em carboidratos-não-fibrosos e pobre em fibra em detergente neutro, no concentrado da dieta de ovinos, e não observaram efeito com a inclução do farelo de cacau para a eficiência em alimentação e ruminação.

Esses resultados foram encontrados, provavelmente devido aos consumos de matéria seca e fibra em detergente neutro (kg/dia) serem semelhantes entre as dietas experimentais. Neste trabalho, os consumos de matéria seca e fibra em detergente neutro ( $\mathrm{kg} / \mathrm{dia})$ apresentaram valores médios, respectivamente, de 16,70 e 6,82 kg (Tabela 5), o que justifica os resultados obtidos para as eficiências, que são diretamente relacionadas ao consumo expresso em $\mathrm{kg} / \mathrm{dia}$.

A eficiência de ruminação (kg FDN/hora) aumentou linearmente. Pois, apesar do tempo de ruminação não ter sido influenciado, numericamente é possível observar uma queda no tempo que os animais levam nessa atividade (Tabela 5), refletindo na eficiência de ruminação (kg FDN/ hora). Portanto, é possível afirmar que os animais, à medida em que se elevava a inclusão de palma, se tornavam mais eficientes, pois eram capazes de ruminar a mesma quantidade de FDN em menos tempo.

\section{Conclusões}

A inclusão de 56\% de palma forrageira na dieta modifica o comportamento ingestivo de ovinos, mas não provoca distúrbio ingestivo nos animais. A substituição total do milho e parcial da soja por $60 \%$ de palma forrageira mais ureia não compromete o comportamento ingestivo de vacas mestiças em lactação. Recomenda-se, para ração de ruminantes com alta proporção de palma forrageira, a inclusão de uma fonte de fibra fisicamente efetiva.

\section{Referências}

ALBRIGHT, J.L. Nutrition, feeding and calves: feeding behavior of dairy cattle. Journal of Dairy Science, v.76, n.2, p.485-498, 1993.

AMORIM, M.C.C.; PORTO, E.R.; SILVA JR., L.G.A. [2004]. Evaporação solar como alternativa de reuso dos efluentes da dessalinização por osmose inversa. Acesso em: <http:// www.cepis.org.pe/bvsaidis/aresidua/i-007>. Acesso em: 30/9/2008.

ASSIS, A.J.; CAMPOS, J.M.S.; VALADARES FILHO, S.C. et al. Polpa cítrica em dietas de vacas em lactação. 1. Consumo de nutrientes, produção e composição do leite. Revista Brasileira de Zootecnia, v.33, n.1, p.242-250, 2004.

BISPO, S.V.; FERREIRA, M.A.; VÉRAS, A.S.C. et al. Palma forrageira em substituição ao feno de capim-elefante. Efeito sobre consumo, digestibilidade e características de fermentação ruminal em ovinos. Revista Brasileira de Zootecnia, v.36, n.6, p.1902-1909, 2007.

BURGUER, P.J.; PEREIRA, J.C.; QUEIROZ, A.C. Comportamento ingestivo em bezerros holandeses alimentados com dietas contendo diferentes níveis de concentrado. Revista Brasileira de Zootecnia, v.29, n.1, p.236-242, 2000.

CARVALHO, G.G.P.; PIRES, A.J.V.; SILVA, F.F. et al. Comportamento ingestivo de cabras leiteiras alimentadas com farelo de cacau ou torta de dendê. Pesquisa Agropecuária Brasileira, v.39, n.9, p.919-925, 2004.

CARVAlHO, G.G.P.; PIRES, A.J.V.; SILVA, R.R. et al. Comportamento ingestivo de ovinos Santa Inês alimentados com dietas contendo farelo de cacau. Revista Brasileira de Zootecnia, v.37, n.4, p.660-665, 2008.

CASALI, A.O.; DETMANN, E.; VALADARES FILHO, S.C. et al. Estimação de teores de componentes fibrosos em alimentos para ruminantes em sacos de diferentes tecidos. Revista Brasileira de Zootecnia, v.38, n.1, p.130-138, 2009.

CHALUPA, W.; SNIFFEN, C.J. Protein and amino acid nutrition of lactating dairy cattle in dairy nutrition management. Veterinary Clinics of North America, v.7, n.2, 353-372, 1991.

COLENBRANDE, V.F.; NOLLER, C.H.; GRANT, R.J. Effect of fiber content and particle size of alfafa silage on performance and chewing behavior. Journal of Dairy Science, v.74, n.8, p.2681-2681, 1991

DOUGHTERTY, C.T.; COLLINS, M. Forage utilization. In: BARNES, R.F.; MILLER, D.A.; NELSON, C.J. (Eds). Forages: 
an introduction to grassland agriculture forages an introduction to glassland agriculture. 6.ed. Ames: Iowa State University Press, 2003. p.391-414.

DULPHY, J.P.; REMOND, B.; THERIEZ, M. Ingestive behaviour and related activities in ruminants. In: RUCKEBUSH, Y., THIVEND, P. (Eds.). Digestive physiology and metabolism in ruminants. Lancaster: MTP, 1980. p.103-122.

FERREIRA, M.A. Palma forrageira na alimentação de bovinos leiteiros. Recife: UFRPE, Imprensa Universitária, 2005. 68p.

FELKER, P. Produção e utilização de forragem. In: BARBERA, G.; INGLESE, P. (Eds.) Agroecologia, cultivos e usos da palma forrageira. Paraíba: SEBRAE/PB, 2001. p.147-157.

GEBREMARIAM, T.; MELAKU, S.; YAMI, A. Effect of wilting of cactus pear (Opuntia ficus-indica) on feed utilization in sheep. Tropical Science, v.46, n.1, p.37-40, 2006.

GRANT, R.J.; ALBRIGTH, J.L. Feeding behaviour and management factors during the transition period in dairy cattle. Journal of Animal Science, v.73, n.12. p.2791-2803, 1995.

HERNANDÉZ, L.F.I.; VALADARES FILHO. S.C.; LANA, R.P. et al. Avaliação de dois métodos in vitro para determinar a cinética ruminal e a digestibilidade intestinal da proteína de vários alimentos. Revista Brasileira de Zootecnia, v.31, n.1, p.256-266, 2002.

HOOVER, W.H. Chemical factors involved in ruminal fiber digestion. Journal of Dairy Science, v.69, n.10, p.2755-2766, 1986.

LIMA, R.M.B.; FERREIRA, M.A.; BRASIL, L.H.A. et al. Substituição do milho por palma forrageira: comportamento ingestivo de vacas mestiças em lactação. Acta Scientiarum Animal Sciences, v.25, n.2, p.347-353, 2003.

LIRA, M.A. Considerações sobre o potencial do sorgo em Pernambuco. In: Curso de extensão sobre a cultura do sorgo. 1981. Brasília, EMBRAPA-DID, 1981. p.47-74.

MARTIN, P.; BATESON, P. Measuring behavior: an introductory guide. 3.ed. New York: Cambridge University Press, 1986. 200p.

MELO, A.A.S.; FERREIRA, M.A.; VÉRAS, A.S.C. et al. Substituição parcial do farelo de soja por uréia e palma forrageira em dietas para vacas em lactação. Digestibilidade. Acta Scientiarum. Animal Sciences, v.25, n.2, p.339-345, 2003

MERTENS, D.R. Creating a system for meeting the fiber requirements of dairy cows. Journal of Dairy Science, v.80, n.7, p.1463-1481, 1997.

MERTENS, D.R. Predicting intake and digestibility using mathematical models of ruminal function. Journal of Animal Science, v.64, n.7, p.1548-58, 1987.

MULLER, C.J.C.; BOTHA, J.A.; SMITH, W.A. Effect of shade on various parameters of Friesian cows in a Mediterranean climate in South Africa. Behavior. Journal of Animal Science, v.24, n.2, p.61-66, 1994.

NATIONAL RESEARCH COUNCIL - NRC. Nutrient requeriments of dairy cattle. 7. rev.ed. Washinton, D.C.: 2001. 381p.

NATIONAL RESEARCH COUNCIL - NRC. Nutrient requirements of small ruminants. Washington, D.C.: National Academy Press, 2007. 362p.

NOBEL, P.S. Ecophysiology of Opuntia ficus-indica. In: MONDRAGÓN-JACOBO, C; PÉREZ-GONZÁLEZ, S. (Eds.)
Cactus (Opuntia spp.) as forage. Rome: Food and Agriculture Organization of the United Nations, 2001. p.13-20. (FAO Plant production and protection paper 169).

OLIVEIRA, A.S.; CAMPOS, J.M.S.; VALADARES FILHO, S.C. et al. Substituição do milho por casca de café ou de soja em dietas para vacas leiteiras: consumo, digestibilidade dos nutrientes, produção e composição do leite. Revista Brasileira de Zootecnia, v.36, n.4, p.1172-1182, 2007 (supl.).

PEREIRA, E.S.; ARRUDA, A.M.V.; MIZUBUTI, I.Y. et al. Consumo voluntário em ruminantes. Ciências Agrárias, v.24, n.1, p.191-196, 2003.

PIRES, M.F.A. [2003]. Raças leiteiras: ambiente e comportamento animal nos trópicos. Foro Electrônico Panamericano sobre Lecheria Tropical,. Disponível em: <http:// www.secnetpro.com/ fepale/documentos 3.htm>. Acesso em: 16/7/2008.

REYNOLDS, S.G.; ARIAS, E. Introduction. In: MONDRAGÓNJACOBO, C.; PÉREZ-GONZÁLEZ, S. (Eds.). Cactus (Opuntia spp.) as forage. Rome: Food and Agriculture Organization of the United Nations, 2001. p.1-4. (FAO Plant production and protection paper 169).

ROSEnBERG, N.J.; BLAD, B.L.; VERMA, S.B. Microclimate: the biological environment. 2.ed. New York: Wiley-interscience Publication, 1983. 495p.

SATTER, L.D.; ROFFLER, R.E. Nitrogen requirement and utilization in dairy cattle. Journal of Dairy Science, v.58, n.8, p.1219-1237, 1975.

SILVA, D.J.; QUEIROZ, A.C. Análise de alimentos: Métodos químicos e biológicos. 3.ed. Viçosa, MG: UFV, 2002. 235p.

SILVA, T.G.F.; TURCO, S.H.N.; MOURA, M.S.B. et al. [2009]. Zoneamento bioclimático para vacas leiteiras no estado de Pernambuco. Disponível em: <http://www.repdigital. cnptia.embrapa.br/bitstream/CPATSA/34027/1/OPB708.pdf > Acesso em: 30/03/2009.

SNIFFEN, C.J.; O’CONNOR, J.D.; VAN SOEST, P.J. et al. A net carbohydrate and protein system for evaluating cattle diets: II. Carbohydrate and protein availability. Journal Animal Science, v.70, n.12, p.3562-3577, 1992.

UNIVERSIDADE FEDERAL DE VIÇOSA - UFV. SAEG - Sistema de análises estatísticas e genéticas. Viçosa, MG: 2000. (CD-ROM).

VAN SOEST, P.J.; ROBERTSON, J.B.; LEWIS, B.A. Methods for extraction fiber, neutral detergent fiber and nonstarch polysaccarides in relation to animal nutrition cows. Journal of Dairy Science, v.83, n.3, p.3583-3597, 1991.

VÉRAS, R.M.L.; FERREIRA, M.A.; VÉRAS, A.S.C. et al. Substituição do milho por farelo de palma forrageira em dietas para ovinos em crescimento. consumo e digestibilidade. Revista Brasileira de Zootecnia, v.34, n.1, p.351-356, 2005.

WANDERLEY, W.L.; FERREIRA, M.A.; ANDRADE, D.K.B. et al. Palma forrageira (Opuntia ficus indica, Mipp) em substituição à silagem de sorgo (Sorghum bicolor (L.)) na alimentação de vacas leiteiras. Revista Brasileira de Zootecnia, v.31, n.1, p.273-281, 2002. 